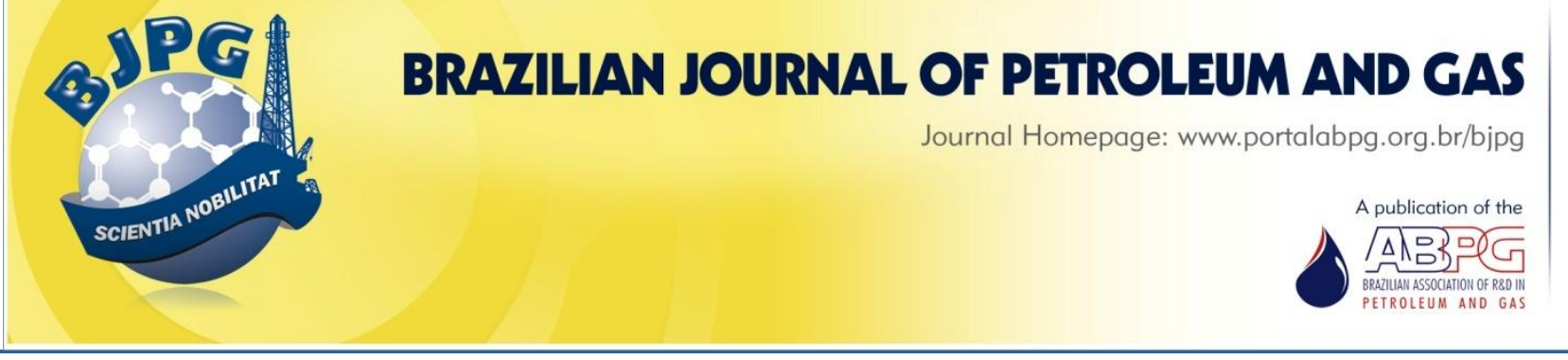

\title{
EFFECTS OF PH AND SOLID CONCENTRATION ON THE RHEOLOGY OF DRILLING FLUIDS COMPOSED BY NATURAL CLAY, WATER, AND NaCMC
}

\author{
${ }^{a}$ Oliveira, B. R.; ${ }^{a}$ Oliveira, R. N.; ${ }^{\text {S }}$ Scheid, C. M.; ${ }^{\text {}}$ Ferraz, A. S. F. S.; ${ }^{\text {b }}$ Marques, M. R. C.; ${ }^{a}$ Calçada, L. A. ${ }^{1}$ \\ ${ }^{\text {a }}$ Federal Rural University of Rio de Janeiro, Institute of Technology, Department of Chemical Engineering, RJ - Brazil \\ ${ }^{b}$ Rio de Janeiro State University, Chemistry Institute, RJ - Brazil
}

Received: 26.01.2018 / Revised: 02.05.2018 / Accepted: 02.05.2018 / Published on line: 11.07.2018

\begin{abstract}
The functions of drilling fluids depend directly on the fluid's physical, chemical, and rheological properties. The selection and control of fluid composition is crucial to obtain the best performance in the process of drilling oil. The presence of solid particulate material and viscosifying agents contributes to the maintenance of the rheological behavior of these fluids. The $\mathrm{pH}$ variation during the drilling may affect rheological properties leading to poor well cleaning and drill string imprisonment. This work aims to evaluate the influence of solid concentration and $\mathrm{pH}$ variation in the rheological behavior of carboxymethyl cellulose and natural clay dispersions. Results indicated that solid concentration increased the apparent viscosity of dispersions due to chemical interactions between the polymer and the particles of natural clay. Dispersions at a $\mathrm{pH}$ lower than five presented lower values of yield stress and apparent viscosity than dispersions with higher $\mathrm{pH}$ values. The protonation of the carboxylic groups of the $\mathrm{NaCMC}$ resulted in a hydrophobicity increase of $\mathrm{NaCMC}$ and in a subsequent reduction of natural clay wettability. The formation of natural clay aggregates caused a decrease in dispersion viscosity.
\end{abstract}

\section{KEYWORDS}

drilling fluids; $\mathrm{pH}$; solid additives; rheology

\footnotetext{
${ }^{1}$ To whom all correspondence should be addressed.

Address: Federal Rural University Rio de Janeiro, PPGEQ - Department of Chemical Engineering, BR 465, Km 7, Campus da UFRRJ, Seropédica-RJ, Brazil.

ZIP Code: 23890-000 | Telephone/Fax: +55 21 3787-8742/+55 21 3787-3750 |e-mail: calcada@ufrri.br doi:10.5419/bjpg2018-0010
} 


\section{INTRODUCTION}

Drilling fluids are multiphased liquid systems composed of mixtures of suspended solids and polymers dissolved in water, among other compounds. These fluids are useful because they perform specific functions during the drilling process. These functions depend directly on the fluids physical, chemical, and rheological properties. It is also known that the fluid's chemical composition is the main factor capable of altering these properties.

It is important to determine the rheological properties of drilling fluids experimentally to improve the drilling operation and reduce the fluid leakage through the producing formations (Majidi et al., 2010). Some factors that influence the rheology of the system are solids concentration, density of the base fluid, temperature, and physical properties of particles and their interactions.

One of the viscosifying agents used in the formulation of drilling fluids is the carboxymethyl cellulose. Despite the carboxymethyl cellulose itself being insoluble in water, its derivatives methylcellulose, ethyl hydroxyethyl cellulose, and sodium carboxymethyl cellulose (NaCMC) are soluble in water. $\mathrm{NaCMC}$ is an anionic polymer that reduces fluid losses by filtration, producing a thin layer with low permeability in borehole wall, increasing the fluid viscosity (Hughes et al., 1993; Lopez et al., 2015).

The apparent viscosity of $\mathrm{NaCMC}$ dispersions varies with the $\mathrm{pH}$ and it is related directly to particles interactions. At a $\mathrm{pH}$ less than $4, \mathrm{a}$ significant increase in apparent viscosity due to the formation of the free acid (less soluble) compounds is obtained and it can even produce insoluble compounds in a pH less than 2 . The greatest stability of this polymer is obtained in the $\mathrm{pH}$ range of 7-9, while at $\mathrm{pH}$ higher than 10 there is a slight decrease in viscosity (Gimenez, 1994).

The alkaline fluid is the most used in drilling operations $(\mathrm{pH} \geq 9)$. Caustic soda and sodium hydroxide are used to reduce the acidity of the fluid. The acidic fluids may cause corrosion of drilling tools; the fluid is less aggressive to the drilling operation when it is alkaline (Safi et al., 2016).

Torrance and Pirnat (1984) studied the effect of
$\mathrm{pH}$ in clay dispersions. They concluded that as the $\mathrm{pH}$ decreases, the yield stress increases until the $\mathrm{pH}$ is about 5.5. Then, it decreases because of the isoelectric point. Khandal and Trados (1988) concluded that in an acid $\mathrm{pH}$ range, the interaction among particles in dispersions of sodium montmorillonite is greater.

In drilling fluids the $\mathrm{pH}$ varies in a basic range, however, when added to the rock formation, a significant variation may occur. If there are regions where this $\mathrm{pH}$ value is naturally different from what is commonly observed, the drilling fluid must be modified.

The aim of this study is to evaluate the sensitivity of rheological parameters of drilling fluids composed by water, sodium carboxymethyl cellulose, and natural clay by observing the variation of $\mathrm{pH}$ in the working regions and clay concentration in the mixture. This article is of fundamental importance for the well drilling process as it is innovative and offers a technological potential.

\section{MATERIALS AND METHODS}

\subsection{X-ray diffraction}

The X-ray diffraction technique was used in chemical and mineralogical characterization of $\mathrm{NaCMC}$ (System Mud) and natural clay (AMC Brasil Minas) particles. The X-ray diffractograms were obtained with a Rigaku Miniflex operating at $30 \mathrm{kV}$ and $15 \mathrm{~mA}$ with Co Ka radiation. The scanning was conducted in the range of $2 \theta=(1-60)^{\circ}$, with acquisition time intervals of $0,050^{\circ}$ and $2 \mathrm{~s}$.

\subsection{Particle-size analysis}

An electromagnetic shaker with sieves (Bertel manufacturer) was used to separate natural clay particles in the same particle-size range. The particle-size distribution of solids was obtained using a Malvern Mastersizer Particle-size analyzer 2000 UM with laser diffraction technique.

\subsection{Fluids preparation}

The fluids were prepared with $\mathrm{NaCMC}$ and different concentrations of natural clay. First, a solution was prepared using deionized water 
$(\mathrm{pH} \approx 7)$ and polymer at $5.70 \mathrm{~g} / \mathrm{L}$. The solution was stirred at $1700 \mathrm{rpm}$ with a Mechanic Mixer Fisatom model 722 for 20 minutes until complete homogenization. The solution density was adjusted in a mud balance Fann model 140 to determine the proper amount of natural clay to achieve densities of $9,9.5$, and $10 \mathrm{lb} / \mathrm{gal}(1078.43,1138.35$, and $1198.26 \mathrm{~g} / \mathrm{L}$ respectively) in $0.35 \mathrm{~L}$ of dispersion. After the addition of clay, fluids were stirred again for 20 minutes until complete homogenization.

To evaluate the influence of the $\mathrm{pH}$, the three dispersions were divided in a total of nine samples with the same volume. One sample of each fluid was acidified by adding concentrated hydrochloric acid. In addition, other sample of each fluid was also altered by adding drops of sodium hydroxide solution $(0.1 \mathrm{M})$ until the fluid $\mathrm{pH}$ remained unchanged. The $\mathrm{pH}$ of the nine samples was evaluated in a pHmeter Model Bel W3B.

\subsection{Rheology}

The rheological tests of the fluids were performed at $25^{\circ} \mathrm{C}$ on a Haake RheoStress 1 rheometer from Thermo Scientific, using the coaxial cylinders geometry, DG43 measuring cup, and DG43-Ti cylindrical rotor. The tests were performed with controlled shear rate in the range of 0 to $1021 \mathrm{~s}^{-1}$ for $120 \mathrm{~s}$.

\section{RESULTS AND DISCUSSION}

\subsection{Mineralogical characterization}

The microstructural evaluation of $\mathrm{NaCMC}$ and natural clay was carried out through the XRD analysis. The $\mathrm{NaCMC}$ polymer and natural clay diffractograms are displayed in Fig. 1 and 2. The analysis of the NaCMC polymer showed peaks at approximately $2 \theta \approx 20^{\circ}$ and $2 \theta \approx 36^{\circ}$, characteristic peaks of carboxymethyl cellulose derivatives (Qi et al., 2015; El Sayed et al., 2015).

The natural clay related phases would be quartz, $\mathrm{SiO}_{2}$ (JCPDS 87-2096); followed by muscovite, $\left(\mathrm{K}, \mathrm{NH}_{4}, \mathrm{Na}\right) \mathrm{Al}_{2}(\mathrm{Si}, \mathrm{Al})_{4} \mathrm{O}_{10}(\mathrm{OH})_{2}$ (JCPDS 461311); kaolinite, $\mathrm{Al}_{2} \mathrm{Si}_{2} \mathrm{O}_{5}(\mathrm{OH})_{4}$ (JCPDS 72-2300); and calcite, $\mathrm{Ca}\left(\mathrm{CO}_{3}\right)$ (JCPDS 86-2334).

At least three peaks of each phase's characteristic diffraction match with the natural clay peaks. The diffraction plans related to each phase's diffraction peaks are also highlighted in Fig. 1. Nonetheless, the presence of quartz and kaolinite is expected in sedimentary clays (Menezes et al., 2003). The studied natural clay consists of calcite, kaolinite, muscovite, and quartz minerals, since these phases peaks match the natural clay peaks.

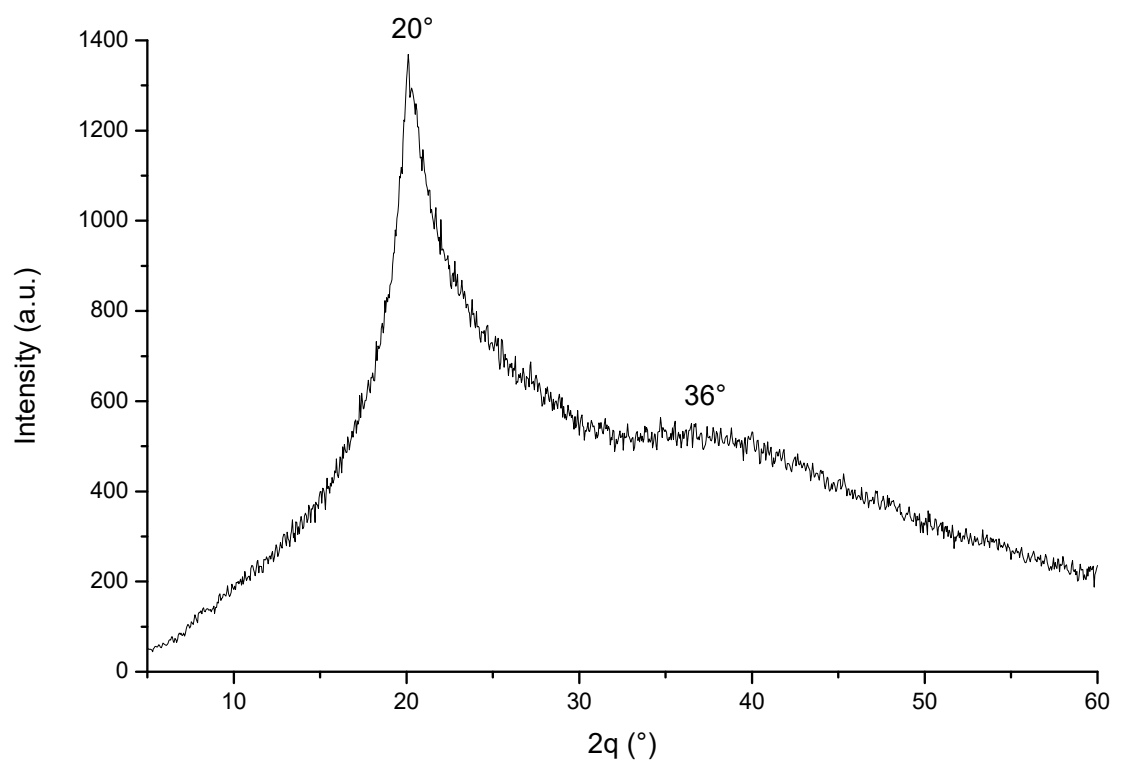

Figure 1. XRD spectrum of NaCMC. 


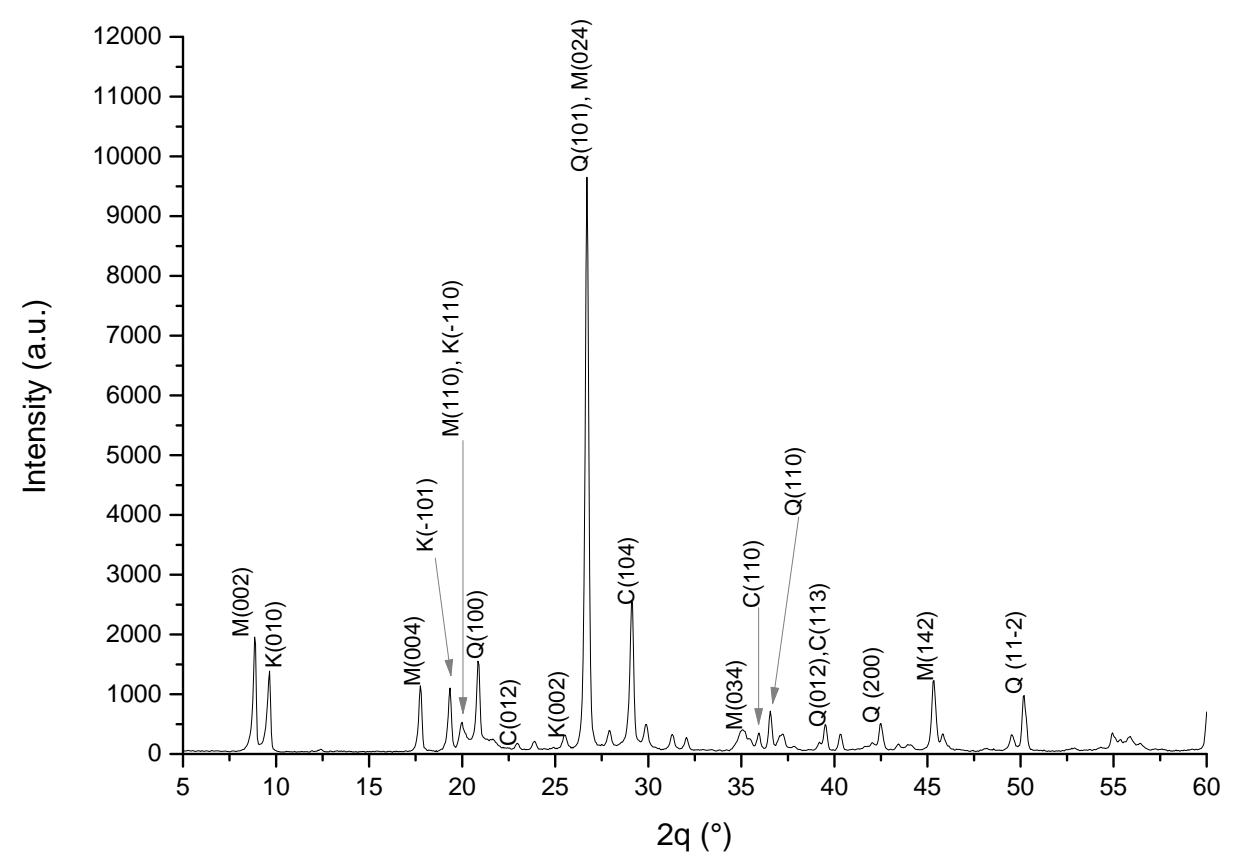

Figure 2. $X R D$ spectrum of natural clay, where $C=$ calcite; $K$ = kaolinite; $M=$ muscovite; $Q=$ quartz.

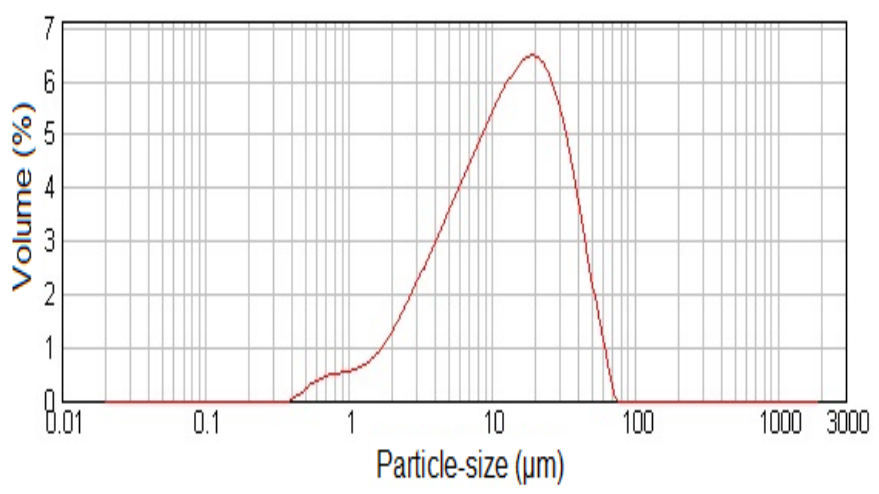

Figure 3. Particle-size distribution of natural clay.

\subsection{Particle-size distribution}

Fig. 3 illustrates the particle-size distribution of natural clay. This solid is composed of small particles with a size range of 0-73 $\mu \mathrm{m}$.

The values of particle-size $2.95,13.15$, and $36.45 \mu \mathrm{m}$ correspond to 10,50 , and $90 \%$, respectively. The Sauter mean diameter was found to be $8.98 \mu \mathrm{m}$.

\subsection{Characterization of $\mathrm{pH}$}

Table 1 presents the measured values of $\mathrm{pH}$ for the dispersions of $\mathrm{NaCMC}$ and natural clay with different densities.

\subsection{Rheology}

Fig. 4 illustrates the shear stress and apparent viscosity curves of $\mathrm{NaCMC}$ and natural clay dispersions with densities of $9,9.5$ and $10 \mathrm{lb} / \mathrm{gal}$.

Table 1. $\mathrm{pH}$ of the dispersions.

\begin{tabular}{cccc}
\hline Density / Dispersion & $\begin{array}{c}\mathbf{9} \\
\text { (lb/gal) }\end{array}$ & $\begin{array}{c}\mathbf{9 . 5} \\
\text { (lb/gal) }\end{array}$ & $\begin{array}{c}\mathbf{1 0} \\
\text { (lb/gal) }\end{array}$ \\
\hline Acidic & 4.77 & 4.58 & 4.7 \\
Neutral & 7.14 & 7.3 & 7.09 \\
Basic & 8.9 & 9 & 9.4 \\
\hline
\end{tabular}



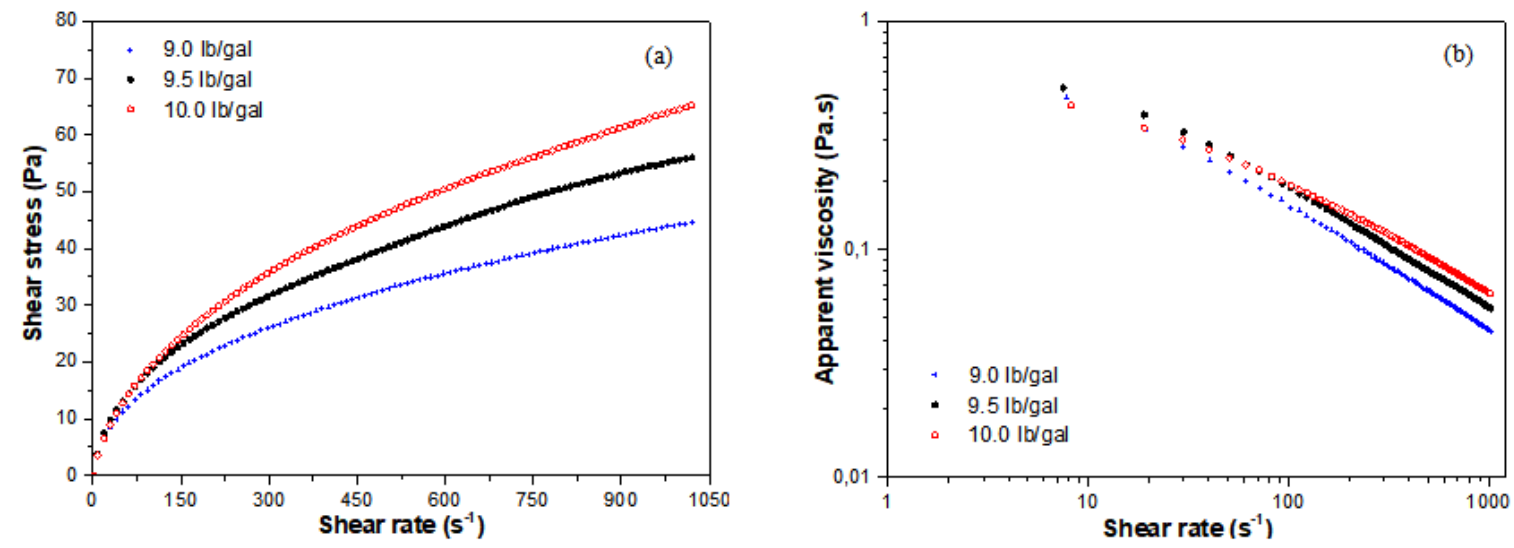

Figure 4. (a) Shear stress and (b) apparent viscosity versus shear rate (NaCMC/natural clay).
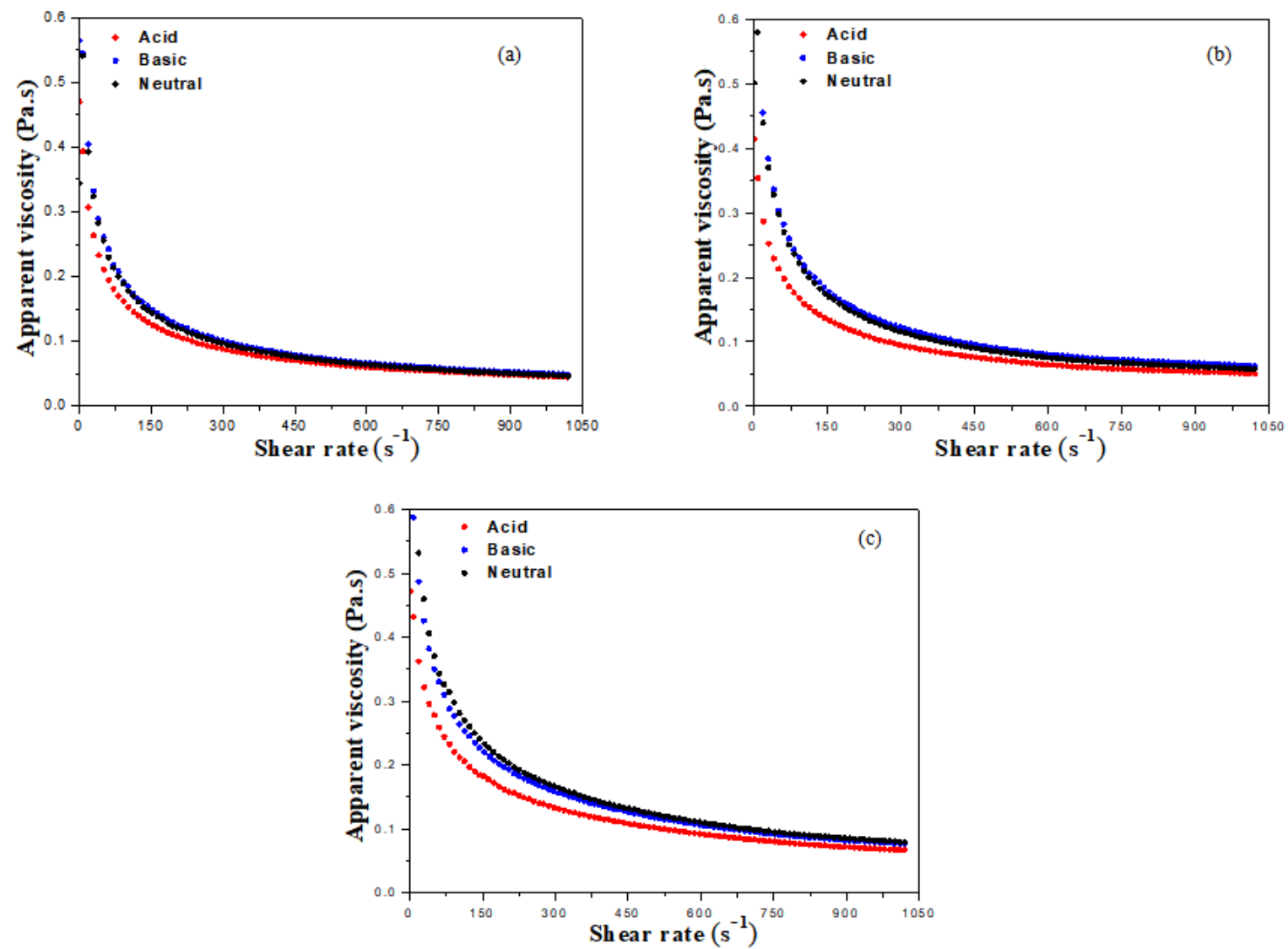

Figure 5. Apparent viscosity versus shear rate for $\mathrm{NaCMC} /$ natural clay dispersions with (a) 9, (b) 9.5, and (c) $10 \mathrm{lb} / \mathrm{gal}$.

The apparent viscosity of these dispersions increased with the concentration of natural clay at a constant shear rate. The viscosity of the drilling fluids is dependent of the solids concentration and in the presence of the NaCMC polymer, the molecular chains entanglement may cause an increase in the apparent viscosity of the dispersion (Käistner et al., 1997). In addition, NaCMC ($\mathrm{CH}_{2} \mathrm{CO}_{2} \mathrm{Na}$ ) groups can interact physically with clay particles, which could also contribute to the apparent viscosity increase resulting in a higher flow resistance. According to Dolz et al. (2007), bentonite clay surface presents non-saturated bonds, which can interact with different substances, particularly with polar ones, i.e. water. If clays can interact with polar groups, they can also interact with $\mathrm{NaCMC}$.

Fig. 5 presents the apparent viscosity curves for dispersions with different hydrogenionic potentials and density values of 9, 9.5, and $10 \mathrm{lb} / \mathrm{gal}$, respectively. 

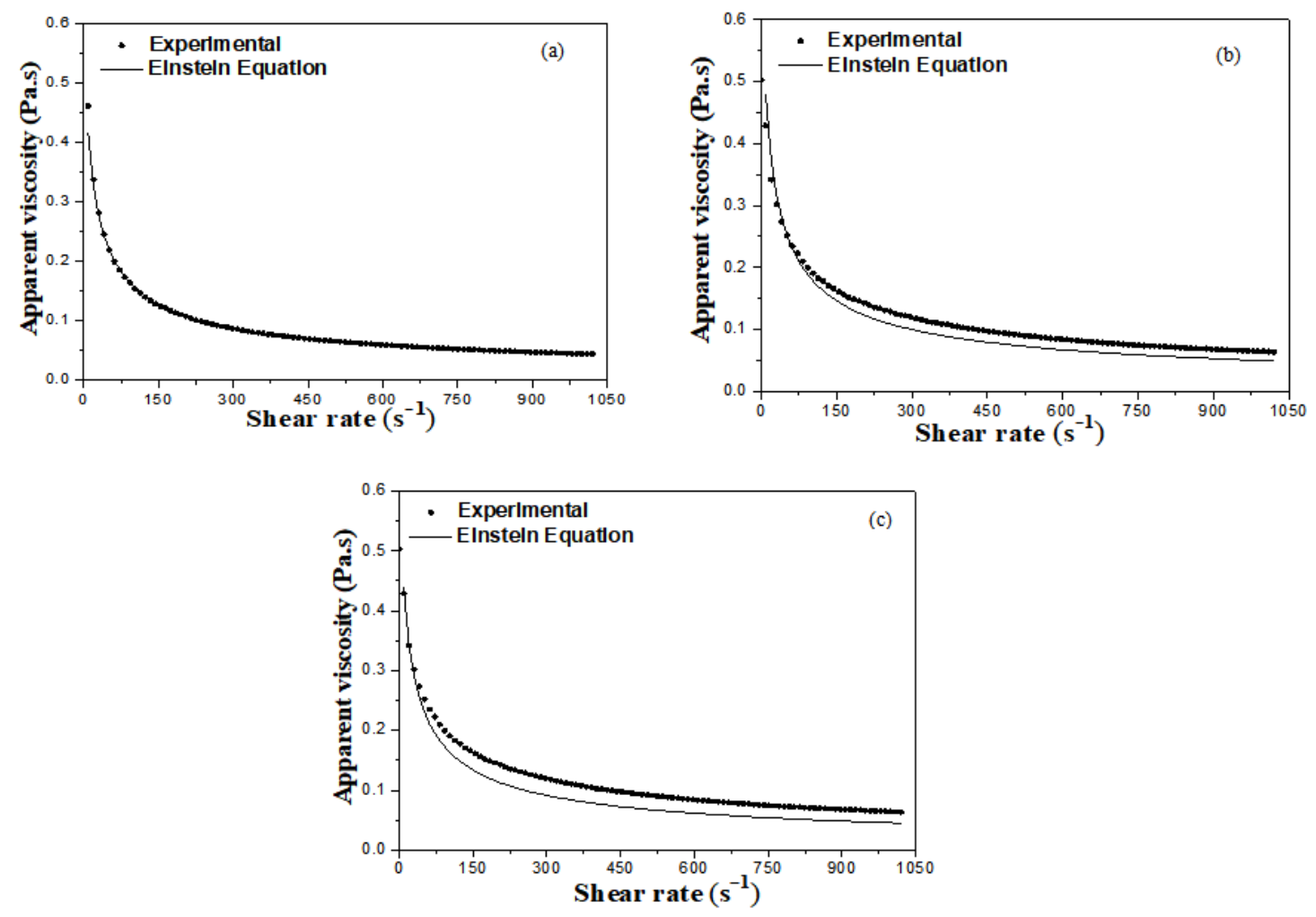

Figure 6. Apparent viscosity versus shear rate for $\mathrm{NaCMC} /$ natural clay dispersions with (a) 9, (b) 9.5 , and (c) 10

$\mathrm{lb} /$ gal with Einstein Equation.

All the acidic dispersions presented a lower apparent viscosity; the higher the density was the lower the viscosity would be, as shown in Fig. 5 . This behavior may be explained by the protonation of the carboxylic groups of the $\mathrm{NaCMC}$, resulting in hydrophobicity increase of $\mathrm{NaCMC}$ and subsequent reduction of natural clay wettability (Alaskari \& Teymoori, 2007). The formation of natural clay aggregates causes the decrease of dispersion viscosity. The base addition did not alter the apparent viscosity of the dispersions significantly.

\subsection{Einstein equation}

Results were analyzed by the Einstein equation to predict the viscosity of a given dispersion by adding solids according to Equation 1. The equation has been proposed for Newtonian fluids, but in this work, $\mu_{\mathrm{L}}$ (Pa.s) is the apparent viscosity of the solution of $\mathrm{NaCMC}$ in water and $\mu_{\mathrm{s}}$ (Pa.s) is the apparent viscosity of the dispersion composed of $\mathrm{NaCMC}$, water, solid particles, and additives (Einstein, 1906).
$\mu_{S}=\mu_{L}(1+\eta \theta)$

Also, $\theta$ is the volumetric fraction of solids and $\eta$ the Einstein coefficient. In sufficiently diluted solutions, when the flow around a sphere is not influenced by the surrounding particles, the value of $\eta$ is equivalent to 2.5 (Larson, 1999).

Fig. 6 presents the apparent viscosity curves for densities of $9,9.5$, and $10 \mathrm{lb} / \mathrm{gal}$ experimentally obtained and compared with those achieved by the Einstein equation.

Fig. 6 shows that all the dispersions were fitted to the Einstein model. As the solid concentration increases, the deviation from the model tends to be higher. This behavior can be explained by the influence of other factors in addition to the suspended solids in the rheology of these fluids. This equation does not consider the effect of $\mathrm{pH}$ and other parameters that affect the properties of dispersions, i.e. the presence of polymers, charged solid particles, and other additives (Mooney, 1951). 


\section{CONCLUSIONS}

The dispersions with higher concentration of natural clay presented higher values of apparent viscosity and yield stress. This behavior was supported by Einstein Equation. This equation considers the solid effects on the rheology of dispersions.

The acid addition reduces the yield stress and apparent viscosity. Nevertheless, this behavior was not observed experimentally. The protonation of the carboxylic groups of the NaCMC resulted in an increase in NaCMC's hydrophobicity and in a subsequent reduction of natural clay wettability. So, the formation of aggregates of natural clay will cause the decrease of dispersion viscosity.

Concerning the Einstein equation evaluation, despite it being a correlation for Newtonian fluid, in this study it was used to fit the viscosity of a nonNewtonian dispersion. The best fit was achieved for the dispersion with lower density. For dispersions with higher solid concentrations, the apparent viscosity obtained by the model diverged from the experimental data. Nonetheless, the equation does not consider other effects as solid charges, polymers, and additives.

\section{ACKNOWLEDGEMENTS}

The authors give thanks for the financial support offered by CENPES (PETROBRAS Research Center, grant No. 460029321) and for the cooperation in scientific support from CAPES and PPGEQ/UFRRJ.

\section{REFERENCES}

Alaskari, M. K. G.; Teymoori, R. N. Effects of salinity, $\mathrm{pH}$ and temperature on $\mathrm{CMC}$ polymer and XC polymer performance. IJE Transactions B: Applications, v. 20(3), p. 283-290, 2007.

Dolz, A.; Jiménez, J.; Jesús Hernández, M.; Delegido, J.; Casanovas, A. Flow and thixotropy of non-contaminating oil drilling fluids formulated with bentonite and sodium carboxymethyl celulose. Journal of Petroleum Science and Engineering, v. 57 (3-4), p. 294-302, 2007. https://doi.org/10.1016/i.petrol.2006.10.008
Einstein A. A new determination of molecular dimensions. Annalen der Physik, v. 4, p. 37-62, 1906.

Gimenez, E. Caracterización hidrogeoquímica de los procesos de salinización en el acuífero detrítico costero de la Plana de Castellon (España). Doctoral thesis, Universidad de Granada, 1994.

Hughes, T. L.; Jones T. G. J.; Houwen O. H. Chemical characterization of CMC and its relationship to drilling-mud rheology and fluids loss. SPE Drilling \& Completion, v. 8(3), p. 157-163, 1993. https://doi.org/10.2118/20000-PA

Käistner, U., Hoffmann, H., Dönges R. and Hilbig, J. Structure and solution properties of sodium carboxymethyl cellulose, Colloids Surfaces A: Physicochemical and Engineering Aspects, v. 123124, p. 307- 328, 1997. https://doi.org/10.1016/S0927-7757(96)03786-7

Khandal, R. K., Tadros, T. F. Application of viscoelastic measurements to the investigation of the swelling of sodium montmorillonite suspensions. Journal of Colloid and Interface Science, v. 125(1), p. 122-128, 1988. https://doi.org/10.1016/0021-9797(88)90060-4

Larson, R. G. The structure and rheology of complex fluids. New York: Oxford University Press. 1999. 663p.

Lopez, C. G.; Rogers, S. E.; Colby, R. H.; Graham, P.; Cabral, J. T. Structure of sodium carboxymethyl cellulose aqueous solutions: A SANS and rheology study. Journal of Polymer Science Part B: Polymer Physics, v. 53, p. 492-501, 2015. https://doi.org/10.1002/polb.23657

Majidi, R.; Miska, S.; Thompson, L. G.; Yu, M.; Zhang, J. Quantitative analysis of mud losses in naturally fractured reservoirs: The effect of rheology. SPE Drilling \& Completion, v. 25 (4), p. 509-517, 2010. https://doi.org/10.2118/114130-PA

Mooney, M. The viscosity of a concentrated suspension of spherical particles. Journal of Colloid Science, v. 6 (2), p. 162-170, 1951. https://doi.org/10.1016/0095-8522(51)90036-0 
Qi, X.-M.; Liu, S.-Y.; Chu, F.-B.; Pang, S.; Liang, Y.R.; Guan, Y.; Peng, F.; Sun, R.-C. Preparation and characterization of blended films from quaternized hemicelluloses and carboxymethyl cellulose. Materials, v. 9 (4), p. 1-12, 2015.

https://doi.org/10.3390/ma9010004

Safi, B.; Zarouri, S.; Chabane-Chaouache, R.; Saidi, M.; Benmounah, A. Physico-chemical and rheological characterization of water-based mud in the presence of polymers. Journal of Petroleum Exploration and Production Technology, v. 6(2), p. 185-190, 2016. https://doi.org/10.1007/s13202$\underline{015-0182-\mathrm{x}}$
El Sayed, A. M.; El-Gamal, S.; Morsi, W. M.; Mohammed, G. Effect of PVA and copper oxide nanoparticles on the structural, optical, and electrical properties of carboxymethyl cellulose films. Journal of Materials Science, v. 50(13), p. 4717-4728, 2015. https://doi.org/10.1007/s10853015-9023-z

Torrance, K. J.; Pirmat, M. Effect of $\mathrm{pH}$ on the rheology of marine clay from the site of the South Nation River, Clays and Clay Minerals, v. 32(5), p. 384-390, 1984. https://doi.org/10.1346/CCMN.1984.0320506 